\title{
Evaluación del desarrollo preimplantacional de embriones murinos in vitro en presencia de Campylobacter fetus venerealis*
}

\author{
Catena, M.; Teruel, M.; Morán, P.; Chiapparrone, M.; Echevarría, H.; Monteavaro, C.; Soto, P. \\ Facultad de Ciencias Veterinarias, UNCPBA, Campus Universitario (B7000GHG), Tandil, Argentina, \\ Tel. 02293-439850.E-mail:mcatena@vet.unicen.edu.ar.
}

\begin{abstract}
Resumen
Catena, M.; Teruel, M.; Morán, P.; Chiapparrone, M.; Echevarría, H.; Monteavaro, C.; Soto, P.: Evaluación del desarrollo preimplantacional de embriones murinos in vitro en presencia de Campylobacter fetus venerealis. Rev. vet. 19: 2, 109-113, 2008. La campylobacteriosis genital bovina es una enfermedad distribuida mundialmente que causa infertilidad y aborto. Los mecanismos relacionados con la patogenia de Campylobacter fetus sobre el embrión bovino son aún poco conocidos. Para estudiar el efecto de Campylobacter fetus venerealis en el desarrollo embrionario se utilizaron mórulas y blastocistos murinos. Las mórulas se cultivaron en medio Ham F10 como grupo control (GA; n: 97), más la adición de Campylobacter fetus venerealis (GB; $\mathrm{n}$ : 129), adicionado con filtrado libre de células (GC; n: 119) y con caldo Brucella (GD; n: 94). Los blastocistos se cultivaron en medio MEM, grupo control (G1: n: 24), y en MEM más suspensión de Campylobacter fetus venerealis, grupo desafiado (G2; n: 35). A partir de mórulas se evaluaron los porcentajes de diferenciación y hatching. En blastocistos se evaluaron los porcentajes de: hatching, hatched, adhesión y expansión. Los resultados se analizaron mediante $\mathrm{Chi}^{2}$. La diferenciación resultó menor a las 24 horas para los grupos GB $(66,6 \%), \mathrm{GC}(65,3 \%)$ y GD $(67,0 \%)$ respecto al control $(82,5 \%$; $\mathrm{p}<0,05)$. A las 48 horas sólo el grupo GC fue menor al control $(70,7 \%$ y $89,6 \%$ respectivamente; $\mathrm{p}<0,05)$. El porcentaje de hatching a las 48 horas fue superior en los grupos GB $(71,2 \%)$ y GC $(70,3 \%)$ respecto al control $(49,4 \% ; \mathrm{p}>0,05)$. A las 72 horas el hatching resultó superior en los grupos GB $(79,2 \%)$ y GC $(83,5 \%)$ comparado con el control $(65,5 \%)$; el GD no mostró diferencias con el control tanto a las 48 como a las 72 horas de cultivo ( $>>0,05)$. En el ensayo de blastocistos no hubo diferencias entre grupos para ninguno de los parámetros evaluados. Se concluye que en este modelo experimental, Campylobacter fetus venerealis no afectó negativamente el desarrollo temprano de embriones murinos, aunque los porcentajes de diferenciación y hatching en GC mostraron diferencias respecto al control.
\end{abstract}

Palabras clave: Campylobacter fetus venerealis, embrión murino, desarrollo preimplantacional.

\begin{abstract}
Catena, M.; Teruel, M.; Morán, P.; Chiapparrone, M.; Echevarría, H.; Monteavaro, C.; Soto, P.: Evaluation of in vitro preimplantational murine embryos development in presence of Campylobacter fetus venerealis. Rev. vet. 19: 2, 109-113, 2008. Bovine campylobacteriosis causes abortion and infertility, and is a worldwide distributed disease. There is a lack of information about the mechanisms of Campylobacter fetus pathogenesis on the bovine embryo. Murine embryos were used to study the effect of Campylobacter fetus on embryo development. Morulae were cultured in Ham F10 as control group (GA; n: 97), with the addition of Campylobacter fetus (GB; n: 129), plus cell-free filtered (GC; n: 119) and Brucella broth (GD; n: 94). Blastocysts were cultured in MEM, control group (G1; n: 24), and in MEM added with Campylobacter fetus venerealis suspension as challenged group (G2; n: 35). Differentiation and hatching percentages were evaluated from morulae. Hatching, hatched, adhesion and expansion percentages were evaluated from blastocysts. Results were analyzed by $\mathrm{Chi}^{2}$ test. Differentiation percentage was less in GB (66.6\%), GC (65.3\%) and GD (67.0\%) than in control group $(82.5 \%$; $\mathrm{p}<0.05)$ at 24 hours, but only in GC group (70.7\%) this percentage was less than control group $(89.6 \%)$ at 48 hours $(\mathrm{p}<0.05)$. Hatching percentage was superior in GB $(71.2 \%)$ and GC $(70.3 \%)$ than in control group $(49.4 \% ; \mathrm{p}<0.05)$ at 48 hours; and was also superior in GB $(79.2 \%)$ and GC $(83.5 \%)$ compared to control group $(65.5 \%$; $p<0.05)$ at 72 hours. There were
\end{abstract}

*Subsidio SECYT 03/H176 “Inmunopatogenia de microorganismos patógenos de la reproducción” (Grupo consolidado SAMP). Recibido: 19 octubre 2008 / Aceptado: 26 noviembre 2008 
no significant differences between GD and control group at 48 and 72 hours ( $p>0.05$ ). Differences were not detected for the evaluated parameters in blastocysts cultures. In conclusion, we observed that for this experimental model, Campylobacter fetus venerealis did not negatively affect the early development of murine embryos, but differentiation and hatching percentages in free-cell filtered group showed differences compared to control group.

Key words: Campylobacter fetus venerealis, murine embryo, preimplantational development

\section{INTRODUCCIÓN}

Para el estudio de las enfermedades de la reproducción se deben tener en cuenta ciertos componentes como el conceptus, la interrelación materno-conceptus y la madre en su medio ambiente ${ }^{1,9,10}$.

La campylobacteriosis genital bovina es una de las enfermedades venéreas de mayor importancia en $\mathrm{Ar}$ gentina ${ }^{4}$. Se caracteriza por presentar signos clínicos que se corresponden con muerte embrionaria y abortos ocasionales 7,11, 14,15. La patogenia está relacionada con los factores de virulencia de la bacteria y la respuesta inmune del huésped. Existen diversas publicaciones que citan como causas de mortalidad embrionaria a los factores de virulencia de Campylobacter fetus, entre ellos su característica de microaerófilo y la producción de mucinasas, que podrían generar cambios tanto en el ambiente uterino como en el oviductal. Dichos cambios, interfieren con el normal desarrollo del embrión durante el período de vida libre, provocando en consecuencia un retardo en la implantación y posteriormente la muerte del embrión ${ }^{23}$. No obstante algunos trabajos de fertilización in vitro de ovocitos bovinos realizados en presencia de Campylobacter fetus venerealis (Cfv) indican que no se afectaría la fertilización, ni el desarrollo embrionario temprano ${ }^{2}$.

Las bacterias patógenas pueden producir daño directo o indirecto sobre la célula huésped mediante mecanismos como la adhesión, la invasión y la capacidad de producir citotoxinas ${ }^{3,5}$. Estos factores de virulencia han sido estudiados en el género Campylobacter en cepas aisladas de seres humanos. La presencia de exotoxinas ha sido confirmada en estudios de citotoxicidad 16, 18,22 y enterotoxicidad ${ }^{20,21}$. En 1993 se comprobó la producción de toxinas citoletales en cultivos de células $\mathrm{CHO}$ infectadas con cepas de Campylobacter fetus fetus aislados de bovinos, planteando el interrogante sobre el efecto de dichas citotoxinas en el embrión ${ }^{19}$.

Los estudios durante la preñez temprana en bovinos resultan dificultosos ya que requieren de un elevado número de hembras preñadas e infectadas, lo cual lleva a la constante búsqueda de diferentes modelos experimentales ${ }^{8,17}$. Con el propósito de utilizar un modelo animal alternativo se realizaron ensayos de infección experimental en ratones, no lográndose reproducir la enfermedad (datos del grupo sin publicar). Dado que dicho modelo no pudo implementarse y considerando las normas de bienestar animal y el costo económico del huésped susceptible (bovinos) se propone un modelo de estudio ex vivo. Con el objetivo de evaluar el efecto de $C f v$ y sus filtrados libres de células (FLC) sobre el desarrollo embrionario temprano, se utilizaron embriones preimplantacionales murinos cultivados in vitro en presencia de la bacteria y del FLC.

\section{MATERIAL Y MÉTODOS}

Animales. El trabajo con los animales fue realizado de acuerdo al Acta de Bienestar Animal de la Facultad de Ciencias Veterinarias (Resolución 087/02 del Consejo Académico, FCV-UNCPBA). Se utilizaron ratones hembras híbridos C57BL6 X BALB/c, de 5 a 8 semanas de edad con un peso entre 20 y $25 \mathrm{~g}$ y machos BALB/c de 12 a 14 semanas, con fertilidad probada. Los animales se mantuvieron bajo un régimen de 12:12 horas luz/oscuridad, con agua y alimento ad libitum. Las hembras fueron inducidas a superovular por inyección intraperitoneal de 10 UI de gonadotrofina coriónica equina (eCG) (Novormon ${ }^{\circledR}$, Laboratorios Syntex, Argentina) y 48 horas más tarde 10 UI de gonadotrofina coriónica humana (hCG) (Profasi ${ }^{\circledR}$, Laboratorios Serono, Méjico). Al tiempo de inyectar la hCG las hembras se colocaron junto a los machos en una relación de 2 hembras/macho. El hallazgo de tapón vaginal a la mañana siguiente al apareamiento se consideró como día uno de preñez.

Cepa bacteriana y condiciones de cultivo. Se utilizó una cepa de Campylobacter fetus venerealis ( $C f$ 27) aislada de mucus cérvico-vaginal de hembra bovina con infección natural, proveniente del cepario del Laboratorio de Microbiología Clínica y Experimental de la Facultad de Ciencias Veterinarias de la UNCPBA. La cepa fue cultivada en medio Skirrow (Merck Art. Núm. 1.02248.0500) durante 3 días, en atmósfera de $10 \%$ de $\mathrm{CO}_{2}, 85 \% \mathrm{~N}_{2}$ y $5 \% \mathrm{O}_{2}$ a $37^{\circ} \mathrm{C}$. Las colonias fueron recolectadas y lavadas con PBS pH 7, 2 mediante centrifugación a $6000 \mathrm{rpm}$ durante 20 minutos y resuspendidas en medio MEM (MEM-EAGLE M0643 Sigma Aldrich) hasta lograr una concentración equivalente al tubo $\mathrm{N}^{\circ} 3$ de la escala de Mac Farland. La morfología bacteriana y pureza de la suspensión fueron controladas mediante coloración de Gram; solamente fueron seleccionadas las colonias que presentaron bacterias con morfología curvo-espiraladas. Los cultivos stock se conservaron a $-70^{\circ} \mathrm{C}$ en caldo glicerol-Tripticasa soja al 15\% (vol/vol) (Merck 13811). 
Recolección de embriones. Las mórulas fueron recolectadas por lavado de oviductos y cuernos uterinos en el tercer día de preñez (69 horas pos-inyección de hCG). Los blastocistos fueron recolectados mediante lavado de cuernos uterinos en el cuarto día de preñez (94 horas pos-inyección de hCG). Los lavados se realizaron con jeringa de $1 \mathrm{ml}$ provista de aguja $\mathrm{N}^{\circ} 30$ con punta roma, utilizando medio de cultivo Ham F10 (Gibco BRL, Life Technologies NY, USA) suplementado con albúmina sérica bovina (BSA) al 0,4\% (Sigma Chemical St Louis, USA).

Cultivo de mórulas: Se cultivaron in vitro grupos de 5 mórulas murinas, en microgotas de $50 \mu \mathrm{l}$ de medio Ham F10 suplementado con $0,4 \%$ de BSA como grupo control (GA; n: 97), con $1 \times 10^{8} C f v / \mathrm{ml}$ (GB; n: 129), con filtrado libre de células (GC; n: 119) y con medio de cultivo bacteriano (GD; n: 94). Todos los cultivos se realizaron en cápsulas Falcon $N^{\circ} 3002(60$ x 15 mm) y las microgotas de medio se mantuvieron cubiertas con vaselina líquida. Los cultivos se realizaron en estufa (Forma Scientific), bajo atmósfera de 5\% de $\mathrm{CO}_{2}, 95 \%$ de aire y a $37^{\circ} \mathrm{C}$ durante 96 horas. Durante el cultivo, los embriones fueron evaluados cada 24 horas para verificar la progresión del desarrollo y la morfología de los mismos.

Cultivo de blastocistos. Los blastocistos recuperados (n: 59 de calidad excelente y buena) se sembraron en placas de cultivo celular de 6 pocillos (Greiner BioOne, Cellstar ${ }^{\circledR}$ TC-plate $\mathrm{N}^{\circ}$ 657160). Se dividieron en 2 grupos al azar, el grupo control (G1; n: 24) 4 embriones/pocillo con $2 \mathrm{ml}$ de MEM y $20 \%$ de suero fetal bovino y el grupo desafiado (G2; n: 35) 5-6 embriones/ pocillo con 1,75 $\mathrm{ml}$ de MEM y $0,25 \mathrm{ml}$ de la suspensión bacteriana de $C f v$. Los embriones se incubaron a $37^{\circ} \mathrm{C}$ bajo atmósfera de $5 \%$ de $\mathrm{CO}_{2}$ y $95 \%$ de aire, durante 96 horas. Se realizaron observaciones diarias con registro fotográfico secuencial para analizar el desarrollo de los embriones in vitro.

Parámetros evaluados. En los cultivos iniciados con embriones en estadío de mórula se determinaron los porcentajes de diferenciación (formación de blastocistos) y hatching (protrusión del blastocisto a través de la zona pelúcida). El primero se determinó a las 24 y 48 horas de cultivo, por la relación entre el número de embriones que alcanzaron el estadío de blastocisto y el total de embriones cultivados. Se consideraron blastocistos morfológicamente normales a aquéllos que presentaron el blastocele y el macizo celular interno bien definidos. Para evaluar el porcentaje de hatching (relación entre el total de embriones que protruyen a través de la zona pelúcida y el total de blastocistos), los embriones fueron controlados a las 48 y 72 horas de cultivo.

En los cultivos iniciados a partir de blastocistos se determinaron los porcentajes de hatching, hatched (embriones que protruyeron a través de la zona pelúcida), adhesión y expansión celular a las 24, 48, 72 y 96 horas de cultivo. Se consideró adhesión cuando los embriones no se separaban del fondo de cada pocillo luego del pipeteo del medio de cultivo y expansión cuando se observó la multiplicación de las células embrionarias adheridas. Se registró la cantidad de blastocistos que presentaron hatching, hatched adhesión y expansión y se calculó el porcentaje relativo al número total de embriones cultivados.

Análisis estadístico. Los porcentajes de diferenciación, hatching, hatched, adhesión y expansión, se analizaron mediante $\mathrm{Chi}^{2}$ estableciéndose un nivel de confianza del $95 \%(\alpha=0,05)$.

\section{RESULTADOS}

Cultivo de embriones a partir de mórulas. El porcentaje de diferenciación a las 24 horas fue menor para los grupos GB $(66,6 \%)$, GC $(65,3 \%)$ y GD $(67 \%)$ comparados con el grupo control $(82,5 \%)(\mathrm{p}<0,05)$. No obstante, a las 48 horas no hubo diferencias entre GB $(78,3 \%)$ y GD $(76,2 \%)$ con respecto al GA $(89,6 \%)$ ( $>0,05)$, mientras que el grupo GC $(70,7 \%)$ fue menor al control ( $p<0,05$; Figura 1$)$.

El porcentaje de hatching a las 48 horas fue superior para los embriones de los grupos GB $(71,2 \%)$ y GC $(70,3 \%)$ comparados con el control $(49,4 \%)$, mientras que el grupo GD $(44,5 \%)$ no mostró diferencias. A las 72 horas se registraron diferencias significativas entre

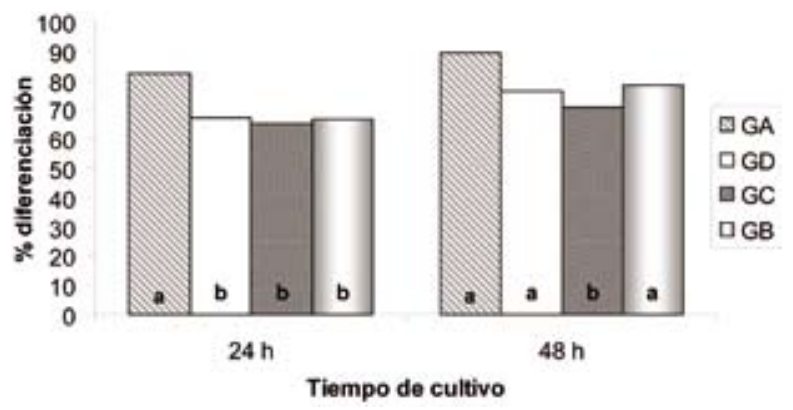

Figura 1. Porcentaje de diferenciación de embriones murinos cultivados con y sin presencia de Campylobacter fetus venerealis. GA: grupo control; GD: grupo con medio de cultivo bacteriano; GC: grupo con filtrado libre de células; GB: grupo con $C f v$. Letras diferentes en cada tiempo de cultivo indican diferencias significativas.

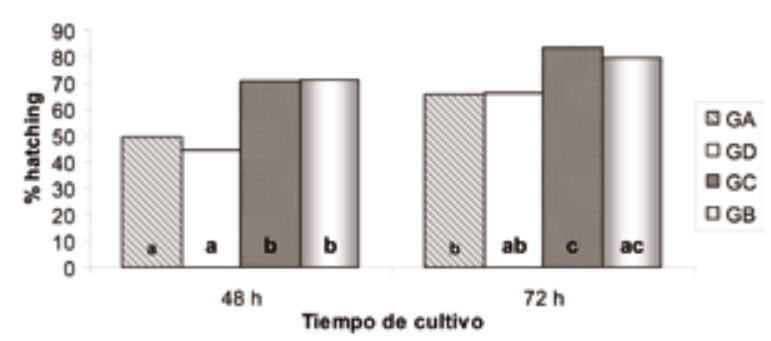

Figura 2. Porcentaje de hatching en embriones murinos cultivados con y sin presencia de Campylobacter fetus venerealis. GA: grupo control; GD: grupo con medio de cultivo bacteriano; GC: grupo con filtrado libre de células; GB: grupo con $C f v$. Letras diferentes en cada tiempo de cultivo indican diferencias significativas. 
Tabla 1. Registro del desarrollo de blastocistos murinos cultivados con y sin presencia de Campylobacter fetus venerealis.

\begin{tabular}{ccccccccccc}
\hline \multirow{2}{*}{$\begin{array}{c}\text { tiempo de } \\
\text { cultivo (h) }\end{array}$} & G1 con zona & \multicolumn{2}{c}{$\%$ hatching } & \multicolumn{2}{c}{$\%$ hatched } & \multicolumn{2}{c}{$\%$ adhesión } & \multicolumn{2}{c}{$\%$ expansión } \\
\hline 24 & 20,8 & 17,2 & 70,8 & 77,2 & 8,4 & 2,8 & & 2,8 & & \\
48 & 4,2 & & & 8,6 & 70,8 & 77,2 & 25,0 & 14,2 & & \\
72 & & & & & & & 75,0 & 77,2 & 25,0 & 22,8 \\
96 & & & & & & & & & 100 & 100 \\
\hline
\end{tabular}

G1: grupo control, G2: grupo desafiado.

los grupos GB $(79,2 \%)$ y GC $(83,5 \%)$ comparados con el control $(65,5 \%)$ mientras que GD $(66,2 \%)$ no mostró diferencias ( $p>0,05$; Figura 2$)$.

Cultivo de embriones a partir de blastocistos. De acuerdo con los resultados obtenidos a las $24,48,72$ y 96 horas no se observaron diferencias significativas en ninguno de los parámetros evaluados entre el grupo de embriones desafiados y el grupo control ( $p>0,05$; Tabla 1). En las figuras 3 y 4 se muestra el registro fotográfico del desarrollo embrionario en los grupos G1 y G2 respectivamente.

\section{DISCUSIÓN}

Las fallas reproductivas durante la gestación temprana son el signo principal de la campylobacteriosis genital bovina ${ }^{14,15}$. El efecto directo de Campylobacter fetus sobre el embrión bovino es uno de los aspectos de la patogenia aún no esclarecido ${ }^{12}$.

El desarrollo de un modelo ex vivo, como es el cultivo de embriones murinos in vitro, nos ha permitido evaluar la acción de Campylobacter fetus durante las diferentes etapas del desarrollo embrionario temprano. Nuestros resultados muestran que si bien en las primeras 24 horas de cultivo se observó una disminución en el porcentaje de diferenciación ante la presencia de $C f v$, dicho parámetro no mostró diferencias con el control al proseguir el desarrollo in vitro de los embriones. Sobre la base de esta observación podría inferirse que, tanto la formación de los tejidos embrionarios derivados del macizo celular interno, como aquellos que forman parte de la placenta fetal derivados del trofoectodermo, no resultarían modificados. Estas observaciones pueden relacionarse con los resultados de ensayos realizados en hembras bovinas infectadas experimentalmente, que a pesar de ser diagnosticadas por ultrasonografía como no preñadas, revelaron la presencia de células trofoblásticas en cortes histológicos de útero, indicando interacción materno-embrionaria ${ }^{6}$. No obstante, debe considerarse que cuando los embriones fueron cultivados en medio Ham F10 más el filtrado libre de células, la diferenciación resultó afectada negativamente tanto a las 24 como a las 48 horas de cultivo. Este resultado podría deberse a un efecto producido por la presencia de embriotoxinas bacterianas presentes en el filtrado.

El proceso de hatching no resultó afectado negativamente por la presencia del Campylobacter fetus ni por el filtrado libre de células, lo cual constituye un dato importante considerando que dicho proceso es un indicador de la viabilidad embrionaria y se relaciona estrechamente con la capacidad de implantación del embrión ${ }^{13}$.

En la segunda parte de este estudio, donde se analizó la relación entre la presencia de $C f v$ y la expansión del embrión una vez perdida la zona pelúcida, nuevamente se observó que los factores de virulencia que pudieran estar presentes en la cepa utilizada, no produjeron interferencia evidente en el desarrollo. Estos datos coinciden con estudios in vitro realizados en ovocitos bovinos, donde la presencia de $C f v$ no afectó la fertili-

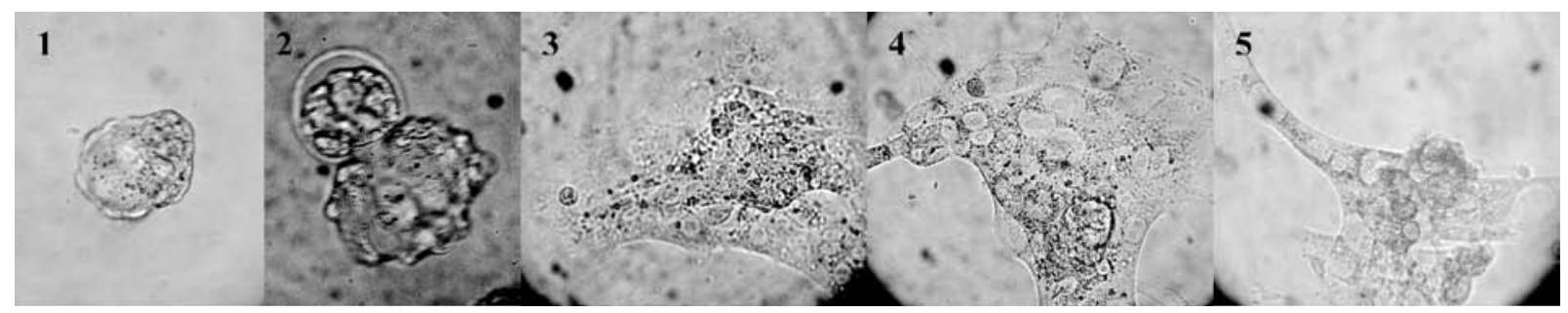

Figura 3. Secuencia embriones grupo control. 1: día 0; 2: 24 h; 3: 48 h; 4: 72 h; 5: 96 h.

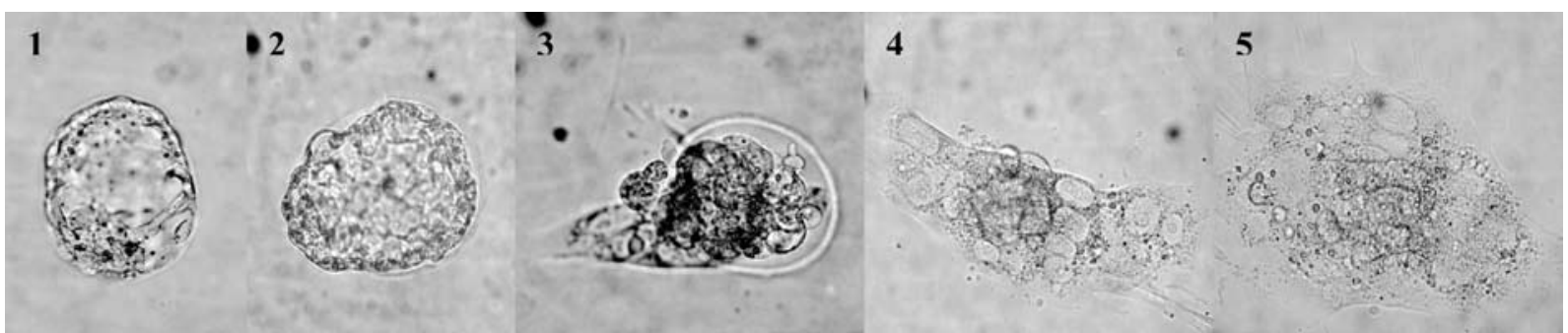

Figura 4. Secuencia embriones grupo desafiado. 1: día 0; 2: 24 h; 3: 48 h; 4: 72 h; 5: 96 h. 
zación ni el desarrollo embrionario temprano ${ }^{23}$. Los resultados obtenidos en los trabajos sobre modelos ex vivo y los realizados en hembras bovinas preñadas ${ }^{6}$ estarían indicando que el factor determinante de la muerte del embrión sería la interacción bacteria-huésped más que la acción directa de la bacteria.

Se concluye que, bajo las condiciones experimentales planteadas en este trabajo, Campylobacter fetus venerealis no interfiere negativamente en el desarrollo temprano de embriones murinos cultivados in vitro, aunque los porcentajes de diferenciación y hatching en el grupo de embriones cultivados con filtrado libre de células mostraron diferencias respecto al control.

\section{REFERENCIAS}

1. Beer A, Billingham R. 1979. Maternal immunological recognition mechanism during pregnancy. Ciba Found Symp 64: 293-322.

2. Bielanski A, Sampath M, Gradil C, Eaglesome M, García M. 1999. In vitro fertilization of bovine ova in the presence of Campylobacter fetus subsp. venerealis. Repr Dom Anim 29: 488-493.

3. Brett Finlay B, Stanley F. 1997. Common themes in microbial pathogenicity revisited. Microbiol \& Mol Biol Revs 61: 136-169.

4. Campero C. 2002. Pérdidas ocasionadas por las enfermedades venéreas de los bovinos. Rev Idia (Buenos Aires) 21: 127-131.

5. Casadevall A, Pirofski L. 2000. Host-pathogen interactions: basic concepts of microbial commensalism, colonization, infection and disease. Infect Immun 68: 6511-6518.

6. Catena M, Callejas S, Soto P, Aba M, Echevarría H, Monteavaro C, Mazzolli A. 2003. Efectos de la infección experimental con Campylobacter fetus venerealis sobre la preñez temprana en vaquillonas. InVet 5: 37-44.

7. Clark B. 1971. Review of bovine vibriosis. Australian Vet J 47: 103-107.

8. Corbeil L. 1980. Criteria for development of animal models of diseases of reproductive system. Am J Pathol 101: 241- 254.

9. Croy B. 1994. Embryo survival in domestic mammals: immunological aspects. In: Embryonic mortality in domestic species (Zavy M, Rodney D, Ed), $2^{\text {nd }}$ ed., p. 153-176.
10. Croy B. 2001. Where now for the Th1/Th2 paradigm of the gestacional uterus? J Reprod Immmunol 51: 1-2.

11. Garcia M, Eaglesome M, Rigby C. 1983. Campylobacters important in veterinary medicine. Vet Bull 53: 793-818.

12. Garcia M, Brooks B. 1993. Campylobacter. Pathogenesis of Bacterial Infections in Animals, Iowa State University Press, $2^{\text {nd }}$ ed., Ames, p. 262-272.

13. Gordon JW, Dapunt U. 1993. Restoration for normal implantation rates in mouse embryos with a hatching impairment by use of a new method of assisted hatching. Fertil Steril 59: 1302-1307.

14. Hoffer M. 1981. Bovine campylobacteriosis: a review. Can Vet J 22: 327-330.

15. Hum S. 1987. Bovine abortion due to Campylobacter fetus. Austr Vet J 64: 319.

16. Johnson W, Lior H. 1987. A new heat-labile cytolethal distending toxin (CLDT) produced by Campylobacter spp. Microbial Path 4: 115-126.

17. McCardell B, Madden J, Stanfield J. 1986. A mouse model for the measurement of virulence of species of Campylobacter. J Infec Dis 153: 177.

18. Misawa N, Ohnishi T, Itoh K, Takaashi E. 1995. Cytotoxin detection in Campylobacter jejuni of human and animal origin with three tissue culture assay systems. $J$ Med Microbiol 43: 354-359.

19. Ohya T, Tominaga K, Nakazawa M. 1993. Production of citolethal distending toxin (CLDT) by Campylobacter fetus subsp. fetus isolates from calves. J Vet Med Sci 55: 507-509.

20. O'Sullivan A, Doré C, Coid C. 1988. Campylobacter and impaired fetal development in mice. J Med Microbiol 25: $7-12$.

21. Roussev R, Stern J, Thorsell L, Thomason E, Coulman C. 1995. Validation of embryotoxicity assay. Am J Reprod Immun 33: 171-174.

22. Tresierra Ayala A, Fernandez H, Reinhardt G, Tadich N, Cabezas X, Zamora J. 1995. Detección de efectos toxigénicos en cepas de Campylobacter jejuni y Campylobacter coli aisladas de bovino. Arch Med Vet 27: 53-59.

23. Ware D. 1979. Pathogenicity of Campylobacter fetus in causing infertility in cattle. Br Vet J 136: 301-303. 